CHRONIC OBSTRUCTIVE PULMONARY DISEASE

\title{
Inhaled corticosteroids and mortality in chronic obstructive pulmonary disease
}

\begin{abstract}
D D Sin, L Wu, J A Anderson, N R Anthonisen, A S Buist, P S Burge, P M Calverley, J E Connett, B Lindmark, R A Pauwelst, D S Postma, J B Soriano, W Szafranski, J Vestbo
\end{abstract}

See end of article for authors' affiliations

Correspondence to: Dr D D Sin, James Hogg iCAPTURE Center for Cardiovascular and Pulmonary Research, St Paul's Hospital, 1081 Burrard Street, Vancouver, BC, Canada, V6Z 1Y6; dsin@mrl.ubc.ca

Received 15 April 2005 Accepted

22 September 2005

Published Online First 14 October 2005
Background: Clinical studies suggest that inhaled corticosteroids reduce exacerbations and improve health status in chronic obstructive pulmonary disease (COPD). However, their effect on mortality is unknown. Methods: A pooled analysis, based on intention to treat, of individual patient data from seven randomised trials (involving 5085 patients) was performed in which the effects of inhaled corticosteroids and placebo were compared over at least 12 months in patients with stable COPD. The end point was all-cause mortality.

Results: Overall, $4 \%$ of the participants died during a mean follow up period of 26 months. Inhaled corticosteroids reduced all-cause mortality by about $25 \%$ relative to placebo. Stratification by individual trials and adjustments for age, sex, baseline post-bronchodilator percentage predicted forced expiratory volume in 1 second, smoking status, and body mass index did not materially change the results (adjusted hazard ratio (HR) 0.73 ; $95 \%$ confidence interval (CI) 0.55 to 0.96 ). Although there was considerable overlap between subgroups in terms of effect sizes, the beneficial effect was especially noticeable in women (adjusted HR $0.46 ; 95 \% \mathrm{Cl} 0.24$ to 0.91 ) and former smokers (adjusted $\mathrm{HR} 0.60 ; 95 \% \mathrm{Cl} 0.39$ to 0.93).

Conclusions: Inhaled corticosteroids reduce all-cause mortality in COPD. Further studies are required to determine whether the survival benefits persist beyond 2-3 years.
C hronic obstructive pulmonary disease (COPD) is a major global epidemic affecting $5-15 \%$ of all adults in lion deaths each year worldwide. ${ }^{3}$ Even more alarmingly, the global burden of COPD will escalate over the next 20 years as more people live longer and a greater number of individuals take up smoking, especially in developing countries. By 2020 the World Health Organization predicts that COPD will be the fifth most prevalent disease (currently twelfth) and the third most common cause of death worldwide (currently fourth). ${ }^{3}$ Unfortunately, apart from smoking cessation, there is a dearth of management strategies available that can curb the rising impact of COPD. ${ }^{1}$ Smoking cessation improves the natural history of COPD. However, once COPD is established, many sustained quitters remain symptomatic and experience frequent exacerbations of their disease. ${ }^{1}$ They also have evidence for persistent airway wall inflammation. ${ }^{4}$ Thus, in symptomatic patients with COPD, additional treatments are indicated.

In view of the prominence and importance of airway inflammation in the pathogenesis of COPD, ${ }^{5}$ anti-inflammatory drugs such as inhaled corticosteroids can potentially improve health outcomes in patients with the disease. However, a few short term physiological studies have failed to demonstrate salutary effects of these medications on inflammatory indices in sputum, ${ }^{67}$ as one might expect given their anti-inflammatory properties, and several long term trials have failed unequivocally to demonstrate a beneficial effect in modifying the long term decline in lung function. ${ }^{8}$ Although several large clinical trials have evaluated the role of inhaled corticosteroids in COPD, none of them individually had sufficient statistical power to assess the effect of inhaled corticosteroids on all-cause mortality, and many did not report on mortality in their original publications. For this reason, prior meta-analyses, which relied on published grouped data, could not adequately evaluate mortality as an end point. $^{8-11}$ To overcome this deficiency and determine whether inhaled corticosteroids affect all-cause and causespecific mortality in COPD, we pooled retrospective individual patient data from the seven large randomised controlled trials evaluating the effects of these medications in stable COPD over a period of at least 1 year. Because some of these trials selectively chose patients with COPD who were actively smoking at the time of enrolment (leading to the overrepresentation of active smokers), we also evaluated the potential effect modification by smoking status and several other factors including sex, age, and baseline lung function.

\section{METHODS}

Studies included: design and treatment

The Inhaled Steroid Effects Evaluation in COPD (ISEEC) study included patient level data from all clinical trials in which patients with stable COPD were randomly assigned to inhaled corticosteroids or placebo for at least 12 months. These trials included the Lung Health Study-2 (LHS-2), ${ }^{12}$ Copenhagen City Lung Study (CCLS), ${ }^{13}$ Inhaled Steroids in Obstructive Lung Disease in Europe (ISOLDE), ${ }^{14}$ European Respiratory Society Study on Chronic Obstructive Pulmonary Disease (EUROSCOP), ${ }^{15}$ TRial of Inhaled STeroids ANd long acting $\beta_{2}$ agonists (TRISTAN), ${ }^{16}$ and trials by Szafranski et al ${ }^{17}$ and Calverley et al. ${ }^{18}$ The full details of the individual trials have been published elsewhere. ${ }^{12-18}$

Participants in these trials were routinely seen at least every 3-6 months by study investigators. Mortality information was collected and collated by study personnel and recorded in the trial databases. Anonymised data collected

${ }^{\dagger}$ Deceased. 
Table 1 Characteristics of individual studies at the time of randomisation

\begin{tabular}{|c|c|c|c|c|c|c|c|c|c|}
\hline Study & $\begin{array}{l}\text { No of } \\
\text { patients }\end{array}$ & $\begin{array}{l}\text { Age } \\
\text { (years) }\end{array}$ & $\begin{array}{l}\text { Women } \\
(\%)\end{array}$ & $\begin{array}{l}\text { Current } \\
\text { smoker (\%) }\end{array}$ & FEV $_{1}(I)^{*}$ & $\begin{array}{l}\mathrm{FEV}_{1}(\% \text { of } \\
\text { predicted })^{\star} \dagger\end{array}$ & $\begin{array}{l}\text { Mortality } \\
(\%)\end{array}$ & $\begin{array}{l}\text { Follow up } \\
\text { (months) }\end{array}$ & Drug/dose \\
\hline LHS-2 & 1116 & $56(7)$ & 37 & 90 & $2.3(0.6)$ & $67(13)$ & 2.8 & $42(5)$ & $\begin{array}{l}\text { Triamcinolone (1200 } \mu \mathrm{g} / \\
\text { day) }\end{array}$ \\
\hline CCLS & 290 & $59(9)$ & 40 & 76 & $2.4(0.8)$ & $76(18)$ & 2.8 & $30(12)$ & Budesonide (867 $\mu \mathrm{g} /$ day) \\
\hline ISOLDE & 751 & $64(7)$ & 25 & 48 & $1.4(0.5)$ & 49 (14) & 13.7 & $34(7)$ & Fluticasone $(1000 \mu \mathrm{g} /$ day $)$ \\
\hline EUROSCOP & 1277 & $52(8)$ & 27 & 100 & $2.6(0.7)$ & 73 (13) & 1.5 & $28(13)$ & Budesonide (800 $\mu \mathrm{g} /$ day) \\
\hline TRISTAN & 735 & $63(9)$ & 28 & 50 & $1.4(0.5)$ & 46 (13) & 2.0 & $10(4)$ & Fluticasone $(1000 \mu \mathrm{g} /$ day $)$ \\
\hline Szafranski & 403 & $64(9)$ & 18 & 30 & $1.0(0.4)$ & $36(12)$ & 3.5 & $9(4)$ & Budesonide ( $800 \mu \mathrm{g} /$ day) \\
\hline Calverley & 513 & $64(9)$ & 26 & 31 & $1.2(0.5)$ & $42(15)$ & 2.1 & $9(5)$ & Budesonide (800 $\mu \mathrm{g} /$ day) \\
\hline Total & 5085 & $59(9)$ & 29 & 69 & $1.9(0.8)$ & $58(19)$ & 4.0 & $26(15)$ & \\
\hline
\end{tabular}

LHS-2, Lung Health Study 2; CCLS, Copenhagen City Lung Study; ISOLDE, Inhaled Steroids in Obstructive Disease in Europe; EUROSCOP, European Respiratory Society Study on Chronic Obstructive Pulmonary Disease; TRISTAN, TRial of Inhaled STeroids ANd long acting $\beta_{2}$ agonists; FEV 1 , forced expiratory volume in 1 second.

*Post-bronchodilator values.

†Values may differ slightly from the original publications because we applied Hankinson's prediction equation to all of the "raw" FEV 1 values.

Continuous variables are presented as mean (SD) and dichotomous variables as percentage of participants in each individual trial.

from the seven individual trials were sent from each trial site to the central ISEEC coordinating centre where they were merged together for analytical purposes. We applied Hankinson's prediction equation to calculate percentage predicted forced expiratory volume in 1 second $\left(\mathrm{FEV}_{1}\right)$ across all studies. ${ }^{19}$ Principal causes of death were classified on reports by study investigators and were categorised into four groups: cardiovascular, respiratory, cancer, and others/ unknown.

\section{Statistical analysis}

For the primary analysis we compared the efficacy of inhaled corticosteroids on all-cause mortality rates based on the original allocation of participants in the individual trials, regardless of whether they did or did not have complete follow up. This end point was chosen a priori. The participants in each trial were followed from the date of enrolment to the date of withdrawal (for whatever reason), death or study completion, whichever came first. In ISOLDE, complete mortality data were obtained on all study participants for 3 years through the UK Office of Population Statistics registry. ${ }^{20}$ In LHS-2, mortality status was established by the investigators for study participants over the duration of the trial. For the other studies, complete mortality data were obtained only on those who completed the trials. Deaths that occurred after the withdrawal date were not ascertained except among those who developed a serious adverse event during the trial period and died before the full resolution of the serious adverse event had occurred.

Kaplan-Meier curves were generated to compare the time to death between the steroid and placebo arms, and the logrank statistic determined the significance of differences between the curves. Cox proportional hazards regression modeling was used to estimate the relative effect of inhaled corticosteroids on all-cause mortality according to confounding variables. Hazard ratios (HR) and the nominal 95\% confidence intervals (CI) were presented. We checked for the proportional hazards assumption visually and by including a time-interaction term to the model and the assumption was met $(p=0.741)$. In the adjusted model we stratified by individual trials which allowed hazard functions to differ for each trial. The model also controlled for age (in quintiles), sex, baseline post-bronchodilator percentage predicted $\mathrm{FEV}_{1}$ (in quintiles), baseline smoking status, and body mass index (BMI; in quintiles) of the trial participants. Secondary analyses included subgroup analyses based on sex, baseline smoking status, and above and below median values for age, baseline $\mathrm{FEV}_{1}$, and BMI. Competing risk models were used to evaluate the hazards of cause-specific mortality. All tests were two tailed in nature and were conducted using SAS 8.2 software (Cary, NC). Continuous variables are shown as mean (SD) unless otherwise indicated.

\section{RESULTS}

The characteristics of the trials included in the ISEEC are summarised in table 1 . In total, data from 5085 participants were analysed. None of the participants (including those who withdrew prematurely) was excluded from the analysis. The baseline characteristics of the trial participants are summarised in table 2 . The mean (SD) age of the participants was 59.0 (9.3) years and the mean post-bronchodilator $\mathrm{FEV}_{1}$ was $58.4(19.5) \%$ of predicted. Nine percent of the cohort $(\mathrm{N}=436)$ were in the Global Initiative for Chronic Obstructive Lung Disease $(\mathrm{GOLD})^{1}$ class $4\left(\mathrm{FEV}_{1}<30 \%\right.$ of predicted $) ; 28 \%(\mathrm{~N}=1419)$ were in GOLD class $3\left(\mathrm{FEV}_{1} 30\right.$ $49 \%$ of predicted $) ; 49 \%(\mathrm{~N}=2466)$ were in GOLD class 2 ( $\mathrm{FEV}_{1} 50-79 \%$ of predicted); and $15 \%(\mathrm{~N}=764)$ were in GOLD class 1 ( $\mathrm{FEV}_{1} \geqslant 80 \%$ of predicted $)$. The mean bronchodilator response was $9(12) \%(0.13(0.15) \mathrm{l})$ from pre-bronchodilator values. $71 \%$ of the participants were men and $69 \%$ were current smokers at the time of enrolment. In total, 973 participants (12\%) withdrew prematurely from EUROSCOP, TRISTAN, and trials by Szafranski and Calverley and, as such, their vital status beyond the date of the study withdrawal could not be determined. In these trials, more participants withdrew prematurely from the placebo than from the steroid arm $(21 \%$ in placebo versus $18 \%$ in the steroid arm; $\mathrm{p}=0.006$ ). The mean length of follow up was 26 (15) months; this was similar in the placebo and steroid arms of the trials.

Overall, $201(4.0 \%)$ of the participants died during the trial period. Those who died during follow up were older (64

Table 2 Baseline characteristics of study participants

\begin{tabular}{lll}
\hline & $\begin{array}{l}\text { Inhaled } \\
\text { corticosteroids }\end{array}$ & Placebo \\
\hline Number of participants & 2543 & 2542 \\
Age at enrolment (years) & $59(9)$ & $59(9)$ \\
Men & $1798(71 \%)$ & $1810(71 \%)$ \\
Body mass index $\left(\mathrm{kg} / \mathrm{m}^{2}\right)$ & $25(5)$ & $25(5)$ \\
Current smokers & $1775(70 \%)$ & $1738(68 \%)$ \\
Baseline post-bronchodilator & $59(19)$ & $58(20)$ \\
FEV $1 \%$ predicted) & $26(15)$ & $26(15)$ \\
Length of follow up (months) & $26(15)$ \\
\hline
\end{tabular}

$\mathrm{FEV}_{1}$, forced expiratory volume in 1 second.

Continuous variables are presented as mean (SD) unless otherwise specified.

Dichotomous variables are presented as number (\% of column totals). 
(7) years $v 58$ (9) years; $\mathrm{p}<0.001)$ and had lower postbronchodilator $\mathrm{FEV}_{1}$ (48\% (17)\% v 59\% (19)\%; p<0.001) at the time of randomisation than those who survived to the end of the study period. Male participants were more likely to die than female participants $(4.5 \% \vee 2.6 \% ; \mathrm{p}=0.002)$. The baseline BMI was similar between those who did and did not die during follow up (25 (5) $\mathrm{kg} / \mathrm{m}^{2}$ v 25 (5) $\mathrm{kg} / \mathrm{m}^{2}$; $\mathrm{p}=0.794)$.

Compared with placebo, participants assigned to inhaled corticosteroids had a lower risk of mortality (HR 0.75; 95\% CI 0.57 to 0.99 ; fig 1 ). Stratification by individual trials and adjustments for age, sex, baseline post-bronchodilator percentage predicted $\mathrm{FEV}_{1}$, baseline smoking status, and BMI did not materially change the results (adjusted HR 0.73; $95 \%$ CI 0.55 to 0.96 ).

The effects of inhaled corticosteroids in the various subgroups are summarised in table 3 . The beneficial effect of inhaled corticosteroids was especially noticeable in women (adjusted HR 0.46 ; 95\% CI 0.24 to 0.91 ), former smokers (adjusted HR 0.60; 95\% CI 0.39 to 0.93 ), and in those whose baseline post-bronchodilator $\mathrm{FEV}_{1}$ was below $60 \%$ of predicted (adjusted HR 0.67; 95\% CI 0.48 to 0.94 ). We chose this $\mathrm{FEV}_{1}$ cut off because it was the median $\mathrm{FEV}_{1}$ value. None of the interaction terms was significant at the $\mathrm{p}<0.05$ level. Subgroup analyses based on GOLD severity classes showed that, in participants in GOLD classes 3 and 4, inhaled corticosteroids reduced mortality (adjusted HR 0.66; 95\% CI 0.45 to 0.96). The effect was non-significant among participants in GOLD class 1 (adjusted HR 0.84; 95\% CI 0.19 to 3.65 ) and 2 (adjusted HR $0.79 ; 95 \%$ CI 0.51 to 1.23 ). The effects of inhaled corticosteroids were similar between fluticasone, budesonide and triamcinolone, although the width of the confidence intervals were different, reflecting the different sizes of the trials. We also performed subgroup analyses in which trials with a follow up time of 12 months or less were excluded. The results were similar whether trials were included or excluded in those with $\mathrm{FEV}_{1}<60 \%$ of predicted. In such patients, the exclusion of these three studies resulted in an HR of 0.67 (95\% CI 0.47 to 0.95 ). There was no significant heterogeneity in the HRs across the trials ( $p$ value for test of heterogeneity 0.93 ; fig 2 ).

The principal causes of death are summarised in table 4 , grouped into four major categories as described above. Most of the deaths were cardiorespiratory in nature $(64 \%$ of all deaths). Approximately $21 \%$ of the deaths were from cancer. Of the 42 cases of carcinoma related deaths, $79 \%$ were attributed to lung cancer $(\mathrm{N}=33)$. Other causes of death (including sudden deaths) and unknown causes accounted

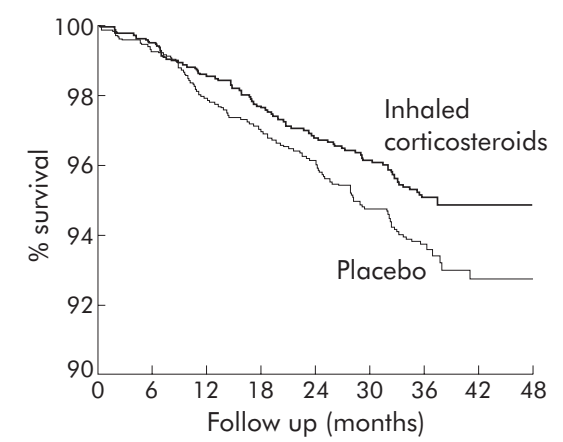

Number $5085441034293023295128932331 \quad 867 \quad 221$ of study participants

Figure 1 Comparison of Kaplan-Meier survival curves between patients treated with inhaled corticosteroids and placebo in COPD (log rank $p=0.039$ ).

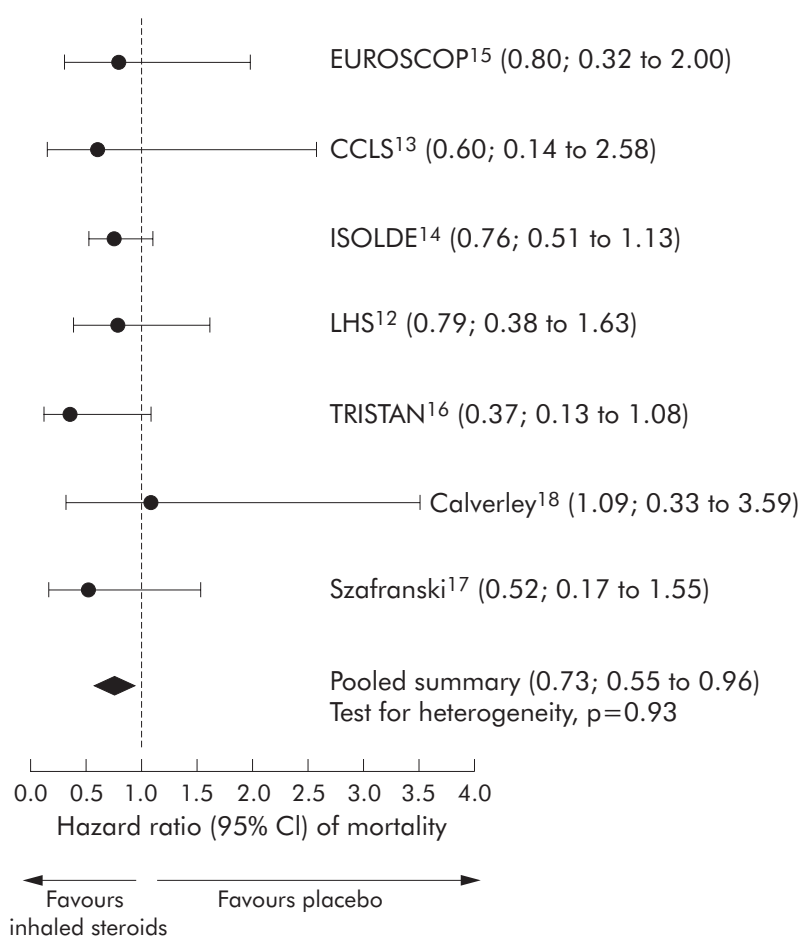

Figure 2 Forest plot of hazard ratios for all-cause mortality across the individual trials. Data are presented as point estimates with $95 \%$ confidence intervals.

for the remaining $15 \%$ of deaths. Because of the small number of deaths in each category, none of the comparisons was significant at the $\mathrm{p}<0.05$ level.

\section{DISCUSSION}

The most important and novel finding of this study is that treatment with inhaled corticosteroids is associated with a $27 \%$ reduction in all-cause mortality in individuals with stable COPD. The beneficial effects of these medications appear to be especially pronounced in women (adjusted HR 0.46 ) and former smokers (adjusted HR 0.60). However, none of the interaction terms was significant so the survival data in the various subgroups should be interpreted cautiously.

This study has some limitations. Firstly, none of the primary studies included in the pooled analysis was designed to evaluate mortality as an end point, which imposed certain restrictions to the pooled analysis. For instance, five of the seven trials included in this pooled analysis did not ascertain mortality information on participants who withdrew prematurely from the trials. In these trials, participants were followed up to the date of withdrawal and any deaths occurring after this date were not recorded in the trial databases, except for those decedents who withdrew initially because of a serious adverse event from the study medication or placebo. As such, those who withdrew prematurely in these trials were recorded as "alive" at the final date of their assessment and any subsequent follow up period they were recorded as "missing." Data from the ISOLDE trial indicate that the placebo group is more likely to withdraw prematurely than the steroid group (53\% $v 44 \%$; $\mathrm{p}=0.008$ ), and mortality is much more likely in those who withdrew prematurely than in those who remain in the trial $(\mathrm{p}<0.001) \cdot{ }^{20}$ It is therefore likely that, by not fully capturing deaths which occurred in the post-withdrawal period, we may have underestimated the true effect of inhaled corticosteroids because the rate of withdrawals was higher in the 
Table 3 Comparison of inhaled corticosteroids and placebo for all-cause mortality per 100 patient-years in the various subgroups

\begin{tabular}{|c|c|c|c|c|}
\hline & $\begin{array}{l}\text { Inhaled } \\
\text { corticosteroids }\end{array}$ & Placebo & Adjusted HR $(95 \% \mathrm{Cl})$ & $\begin{array}{l}\text { p value for } \\
\text { interaction }\end{array}$ \\
\hline Overall & 1.57 & 2.10 & 0.73 (0.55 to 0.96$)$ & \\
\hline \multicolumn{5}{|l|}{ Age (years) } \\
\hline$<60$ & 0.57 & 0.93 & 0.60 (0.33 to 1.07$)$ & \multirow[t]{2}{*}{0.443} \\
\hline$\geqslant 60$ & 2.91 & 3.67 & $0.77(0.56$ to 1.06$)$ & \\
\hline \multicolumn{5}{|c|}{ 年 } \\
\hline Women & 0.77 & 1.53 & $0.46(0.24$ to 0.91$)$ & \multirow[t]{2}{*}{0.234} \\
\hline Men & 1.93 & 2.36 & 0.80 (0.58 to 1.09$)$ & \\
\hline \multicolumn{5}{|l|}{ BMI $\left(\mathrm{kg} / \mathrm{m}^{2}\right)$} \\
\hline$<25$ & 1.67 & 2.32 & $0.68(0.47$ to 0.99$)$ & \multirow{2}{*}{0.686} \\
\hline$\geqslant 25$ & 1.43 & 1.90 & $0.77(0.50$ to 1.17$)$ & \\
\hline \multicolumn{5}{|l|}{ Smoking status } \\
\hline Current & 1.23 & 1.44 & 0.87 (0.59 to 1.22 ) & \multirow[t]{2}{*}{0.231} \\
\hline Former & 2.79 & 4.52 & 0.60 (0.39 to 0.93$)$ & \\
\hline \multicolumn{5}{|l|}{ Baseline $\mathrm{FEV}_{1}$} \\
\hline$<60 \%$ of predicted & 2.71 & 3.86 & $0.67(0.48$ to 0.94$)$ & \multirow[t]{2}{*}{0.707} \\
\hline$\geqslant 60 \%$ of predicted & 0.83 & 0.91 & $0.90(0.54$ to 1.53$)$ & \\
\hline \multicolumn{5}{|l|}{ Length of study } \\
\hline$\leqslant 12$ months & 2.43 & 4.06 & $0.58(0.31$ to 1.10$)$ & \multirow[t]{2}{*}{0.609} \\
\hline$>12$ months & 1.46 & 1.86 & 0.77 (0.56 to 1.05$)$ & \\
\hline \multicolumn{5}{|l|}{ Study medication } \\
\hline Fluticasone & 3.61 & 5.18 & $0.70(0.48$ to 1.01$)$ & \multirow[t]{3}{*}{0.944} \\
\hline Budesonide & 1.04 & 1.33 & $0.73(0.42$ to 1.27$)$ & \\
\hline Triamcinolone & 0.73 & 0.88 & $0.79(0.38$ to 1.63$)$ & \\
\hline
\end{tabular}

placebo arms than in the steroid arms of the trials and these participants tended to be sicker and to have a more rapid decline in $\mathrm{FEV}_{\mathrm{l}}{ }^{21}$ Indeed, in the trials in which complete mortality information was present (LHS-2, ISOLDE), inhaled corticosteroids were effective in reducing all-cause mortality in patients with COPD who had $\mathrm{FEV}_{1}<60 \%$ of predicted (adjusted HR $0.60 ; 95 \%$ CI 0.40 to 0.91 ). In contrast, in the other five trials in which complete mortality data were not available for participants who prematurely dropped out, the adjusted HR was 0.69 (95\% CI 0.37 to 1.30 ).

Secondly, there was a lack of information on long term serious adverse events. The trials included in this analysis were too short to determine the long term effects of inhaled corticosteroids on such outcomes as hip fractures and glaucoma. In the short term at least, in the two trials that collected information on fractures (EUROSCOP and ISOLDE), inhaled corticosteroids did not appear to increase the risk of fractures (relative risk 0.70; 95\% CI 0.36 to 1.38). ${ }^{11}$ Thus, to assess formally whether the benefits in the current pooled analysis outweigh the adverse effects, there needs to be long term clinical studies to define better the risk of important side effects related to inhaled steroid treatment. A third limitation was the difference in investigational medications between the trials. It was reassuring that we did not observe any significant differences between the different formulations, suggesting a class effect of these medications on mortality. Because the trials used relatively homogeneous dosing schedules for specific inhaled corticosteroids, we could not determine whether different doses produced differential outcomes in COPD patients. Finally, as with most pooled and meta-analyses, publication bias is a source of concern. To mitigate this possibility we included all studies that met the inclusion and exclusion criteria, even those with a relatively short follow up period ( 12 months). We found three such trials. Their inclusion was also important to model accurately the effects of inhaled corticosteroids on mortality during the first 12 months of treatment.

The current study cannot determine the potential mechanisms by which inhaled corticosteroids reduce all-cause mortality in COPD. However, since exacerbations increase both the acute and long term risk of mortality in COPD, ${ }^{22}$ these medications may confer survival advantage by reducing the frequency of moderate to severe exacerbations by nearly a third. ${ }^{10}$ The beneficial effects on exacerbations are most obvious in participants with spirometrically defined moderate to severe disease. ${ }^{23}$ It was in these participants $\left(\mathrm{FEV}_{1}<60 \%\right.$ predicted) that the effect of treatment on mortality was seen, and not in those individuals with less impaired lung function where death was infrequent. In addition, these medications improve the health status of participants with moderate to severe disease. ${ }^{14}$ Reduced health status has been associated with both increased frequency of exacerbations ${ }^{24}$ and

Table 4 Comparison of clinical characteristics of patients who died from various causes of mortality and the effect of corticosteroids for these causes of mortality

\begin{tabular}{lllll}
\hline & Respiratory & Cardiovascular & Cancer & Others \\
\hline Total number of deaths & 69 & 60 & 42 & 30 \\
Mean (SD) age (years) & $66.1(6.6)$ & $63.5(7.0)$ & $63.8(6.3)$ & $30(71.4 \%)$ \\
Men & $59(85.5 \%)$ & $50(83.3 \%)$ & $57.8(17.0)$ & $23(76.7 \%)$ \\
Baseline FEV $1 \%$ of predicted) & $39.1(13.1)$ & $51.7(17.1)$ & $0.55(0.29$ to 1.03$)$ & $0.57(0.27$ to 1.19$)$ \\
Adjusted HR (95\% CI) for mortality between & $0.80(0.50$ to 1.28$)$ & $0.98(0.59$ to 1.62$)$ & \\
ICS and placebo groups & & & & \\
\hline
\end{tabular}

Hazard ratios (HRs) were adjusted for age, sex, baseline post-bronchodilator FEV 1 , smoking status, body mass index, and individual trial (see Methods section for Hazard ratios (HRs) were adjusted for age, sex, baseline post-bronchodilator
details). $\mathrm{FEV}_{1}$, forced expiratory volume in 1 second; ICS, inhaled corticosteroids. 
mortality. ${ }^{25}$ Inhaled corticosteroids also have a small effect on attenuating airway hyperresponsiveness, ${ }^{12}$ which is found in $60-80 \%$ of patients with mild to moderate COPD. ${ }^{26}$ Increased airway hyperresponsiveness has been linked to increased COPD mortality. ${ }^{27}$ Interestingly, airway hyperresponsiveness is more common in women than in men with COPD. ${ }^{26}$ The relative importance of these potential mechanisms requires further exploration.

This study was underpowered to evaluate the effects of inhaled corticosteroids on specific causes of mortality. However, there was a trend towards a lower risk of cancer related mortality for those randomised to inhaled corticosteroids. Whether or not this is a real effect will require further study. Chronic inflammation has been implicated in the development of malignant diseases. ${ }^{28}$ In particular, cycloxygenase (COX)-2 enzymatic activities may regulate immune responses that promote tumour growth. ${ }^{29}$ Inhaled corticosteroids over 6 months have been shown to reduce prostaglandin $\mathrm{E}_{2}$ levels, a product of COX-2 pathways, and to downregulate proto-oncogene (for example, BCL2) expression in the airways of smokers..$^{30}$ In murine models, corticosteroids modulate proto-oncogene expression and inhibit tumour growth by as much as $70 \% .^{31}$ A prospectively randomised population of a similar size and follow up to this one will be needed to address these issues in patients with COPD.

Intriguingly, inhaled corticosteroids may be more effective in former than in current smokers. This pattern has also been observed in asthma. ${ }^{32}{ }^{33}$ Acutely in COPD, smokers have a lower therapeutic response to oral corticosteroids than former smokers. ${ }^{34}$ It has been postulated that smoking induces a state of relative steroid resistance by increasing oxidative stress $^{35}$ and by upregulating production of various proinflammatory cytokines including interleukin-6 (Il-6), IL-8, IL-1 $\beta$, and monocyte chemoattractant protein-1. ${ }^{36}$ Additionally, cigarette smoke appears to reduce histone deacetylase activity and its expression in alveolar macrophages, making these cells relatively resistant to corticosteroids since one of the principal targets of corticosteroid action is by switching off gene expression of inflammatory genes through the recruitment of histone decetylases. ${ }^{37}$ Consistent with these findings, our data suggest that, for patients with COPD to experience maximal benefit from inhaled corticosteroids, cessation of smoking is of prime importance. Because the individual trials included in the current pooled analysis were originally designed and conducted at a time when anti-inflammatory drugs were thought to be most helpful in smokers with COPD, trials generally oversampled the smoking subpopulation of COPD patients. This may have attenuated (or even negated) the beneficial effects of inhaled corticosteroids observed in these studies.

In summary, the present pooled analysis indicates that inhaled corticosteroids are likely to be effective in reducing all-cause mortality in stable COPD. Further research is needed to understand better the molecular and physiological mechanisms by which inhaled corticosteroids reduce mortality in COPD.

\section{ACKNOWLEDGEMENT}

The authors dedicate this paper to the fond memory of their loving friend and colleague, Professor Romain Pauwels.

\section{Authors' affiliations}

D D Sin, The James Hogg iCAPTURE Center for Cardiovascular and Pulmonary Research, St Paul's Hospital, Vancouver, British Columbia, Canada

D D Sin, L Wu, Department of Medicine, University of British Columbia, Vancouver, British Columbia, Canada

J A Anderson, Department of Medical Statistics, GlaxoSmithKline R\&D, UK
N R Anthonisen, Department of Medicine, University of Manitoba, Winnipeg, Manitoba, Canada

A S Buist, Department of Medicine, Oregon Health and Science University, Portland, Oregon, USA

P S Burge, Heartlands Hospital NHS Trust, Birmingham, UK

P M Calverley, University Hospital Aintree, Liverpool, UK

J E Connett, Division of Biostatistics, School of Public Health, University

of Minnesota, Minneapolis, Minnesota, USA

B Lindmark, AstraZeneca R\&D, Lund, Sweden

R A Pauwels, Department of Respiratory Diseases, Ghent University Hospital, Ghent, Belgium

D S Postma, Department of Pulmonology, University of Groningen, the Netherlands

J B Soriano, Fundación Caubcc-Cimera, Palma de Mallorca, Balearic Islands, Spain

W Szafranski, Department of Lung Diseases, Voivodeship Specialist Hospital, Radom, Poland

J Vestbo, South Manchester University Hospital NHS Trust,

Wythenshawe Hospital, Manchester, UK

This work was funded in part by the Michael Smith/St Paul's Hospital Foundation for Health Research and by a Canada Research Chair.

Competing interests: DDS has received honoraria for speaking engagements from AstraZeneca (AZ) and GlaxoSmithKline (GSK) and has received consultancy fees and research funding from GSK. JV has received honoraria for speaking engagements and research funding from $A Z$ and GSK. JAA is currently an employee of GSK R\&D, manufacturer of respiratory drugs. JBS was an employee of GSK. PMAC has received honoraria for speaking engagements and research funding from $A Z$ and GSK. RP received honoraria for speaking engagements and research funding from $A Z$ and GSK. NRA and ASB are members of a respiratory advisory board for GSK. BL is currently an employee of $A Z$, manufacturer of respiratory drugs. DSP has received honoraria for speaking engagements and research funding from AZ and GSK.

\section{REFERENCES}

1 Pauwels RA, Buist AS, Calverley PM, et al. Global strategy for the diagnosis, management, and prevention of chronic obstructive pulmonary disease. NHLBI/WHO Global Initiative for Chronic Obstructive Lung Disease (GOLD) Workshop summary. Am J Respir Crit Care Med 2001;163:1256-76.

2 Anto JM, Vermeire P, Vestbo J, et al. Epidemiology of chronic obstructive pulmonary disease. Eur Respir J 2001;17:982-94.

3 Murray CJ, Lopez AD. Alternative projections of mortality and disability by cause 1990-2020: Global Burden of Disease Study. Lancet 1997;349:1498-504.

4 Rutgers SR, Postma DS, ten Hacken NH, et al. Ongoing airway inflammation in patients with COPD who do not currently smoke. Thorax 2000;55:12-8.

5 Barnes PJ, Shapiro SD, Pauwels RA. Chronic obstructive pulmonary disease: molecular and cellular mechanisms. Eur Respir J 2003;22:672-88.

6 Keatings VM, Jatakanon A, Worsdell YM, et al. Effects of inhaled and oral glucocorticoids on inflammatory indices in asthma and COPD. Am J Respir Crit Care Med 1997; 155:542-8.

7 Culpitt SV, Maziak W, Loukidis S, et al. Effect of high dose inhaled steroid on cells, cytokines, and proteases in induced sputum in chronic obstructive pulmonary disease. Am J Respir Crit Care Med 1999;160:1635-9.

8 Highland KB, Strange C, Heffner JE. Long-term effects of inhaled corticosteroids on $\mathrm{FEV} 1$ in patients with chronic obstructive pulmonary disease. A meta-analysis. Ann Intern Med 2003;138:969-73.

9 Sutherland ER, Allmers H, Ayas NT, et al. Inhaled corticosteroids reduce the progression of airflow limitation in chronic obstructive pulmonary disease: a meta-analysis. Thorax 2003;58:937-41.

10 Alsaeedi A, Sin DD, McAlister FA. The effects of inhaled corticosteroids in chronic obstructive pulmonary disease: a systematic review of randomised placebo-controlled trials. Am J Med 2002;113:59-65.

11 Sin DD, McAlister FA, Man SF, et al. Contemporary management of chronic obstructive pulmonary disease: scientific review. JAMA 2003;290:2301-12.

12 Lung Health Study Research Group. Effect of inhaled triamcinolone on the decline in pulmonary function in chronic obstructive pulmonary disease. N Engl J Med 2000;343:1902-9.

13 Vestbo J, Srensen T, Lange $P$, et al. Long-term effect of inhaled budesonide in mild and moderate chronic obstructive pulmonary disease: a randomised controlled trial. Lancet 1999;353:1819-23.

14 Burge PS, Calverley PM, Jones PW, et al. Randomised, double blind, placebo controlled study of fluticasone propionate in patients with moderate to severe chronic obstructive pulmonary disease: the ISOLDE trial. BMJ 2000;320: 1297-303.

15 Pauwels RA, Lofdahl CG, Laitinen LA, et al. Long-term treatment with inhaled budesonide in persons with mild chronic obstructive pulmonary disease who continue smoking. European Respiratory Society Study on Chronic Obstructive Pulmonary Disease. N Engl J Med 1999;340:1948-53. 
16 Calverley PM, Pauwels R, Vestbo J, et al. Combined salmeterol and fluticasone in the treatment of chronic obstructive pulmonary disease: randomised controlled trial. Lancet. Lancet 2003;361:449-56.

17 Szafranski W, Cukier A, Ramirez A, et al. Efficacy and safety of budesonide/ formoterol in the management of chronic obstructive pulmonary disease. Eur Respir J 2003;21:74-81.

18 Calverley PM, Boonsawat W, Cseke Z, et al. Maintenance therapy with budesonide and formoterol in chronic obstructive pulmonary disease. Eur Resp J 2003;22:912-8.

19 Hankinson JL, Odencrantz JR, Fedan KB. Spirometric reference values from a sample of the general U.S. population. Am J Respir Crit Care Med 1999:159:179-87.

20 Waterhouse JC, Fishwick D, Burge PS, et al. What Caused Death in the ISOLDE Study? Eur Respir J 1999; 14(Suppl. 30):387S.

21 Calverley PM, Spencer S, Willits $L$, et al. Withdrawal from treatment as an outcome in the ISOLDE study of COPD. Chest 2003;124:1350-6.

22 Almagro $P$, Calbo $E$, Ochoa de Echaguen A, et al. Mortality after hospitalization for COPD. Chest 2002;121:1441-8.

23 Jones PW, Willits LR, Burge PS, et al. Disease severity and the effect of fluticasone propionate on chronic obstructive pulmonary disease exacerbations. Eur Respir J 2003;21:68-73.

24 Spencer S, Calverley PM, Burge PS, et al. Impact of preventing exacerbations on deterioration of health status in COPD. Eur Respir J 2004;23:698-702.

25 Domingo-Salvany A, Lamarca R, Ferrer $M$, et al. Health-related quality of life and mortality in male patients with chronic obstructive pulmonary disease. Am J Respir Crit Care Med 2002; 166:680-685

26 Kanner RE, Connett JE, Altose MD, et al. Gender difference in airway hyperresponsiveness in smokers with mild COPD. The Lung Health Study. Am J Respir Crit Care Med 1994;150:956-61.
27 Hospers JJ, Postma DS, Rijcken B, et al. Histamine airway hyperresponsiveness and mortality from chronic obstructive pulmonary disease: a cohort study. Lancet 2000;356:1313-7.

28 Ardies CM. Inflammation as cause for scar cancers of the lung. Integr Cancer Ther 2003;2:238-46.

29 Brown JR, DuBois RN. Cyclooxygenase as a target in lung cancer. Clin Cancer Res 2004; 10:4266s-9s.

30 Lam S, leRiche JC, McWilliams A, et al. A randomized phase llb trial of pulmicort turbuhaler (budesonide) in people with dysplasia of the bronchial epithelium. Clin Cancer Res 2004;10:6502-11.

31 Yao R, Wang Y, Lemon WJ, et al. Budesonide exerts its chemopreventive efficacy during mouse lung tumorigenesis by modulating gene expressions. Oncogene 2004;23:7746-52.

32 Chalmers GW, Macleod KJ, Little SA, et al. Influence of cigarette smoking on inhaled corticosteroid treatment in mild asthma. Thorax 2002;57:226-30.

33 Pedersen B, Dahl R, Karlstrom R, et al. Eosinophil and neutrophil activity in asthma in a one-year trial with inhaled budesonide. The impact of smoking Am J Respir Crit Care Med 1996;153:1519-29.

34 Burge PS, Calverley PM, Jones PW, et al. Prednisolone response in patients with chronic obstructive pulmonary disease: results from the ISOLDE study. Thorax 2003;58:654-8.

35 Maestrelli P, El Messlemani AH, De Fina O, et al. Increased expression of heme oxygenase $(\mathrm{HO})-1$ in alveolar spaces and $\mathrm{HO}-2$ in alveolar walls of smokers. Am J Respir Crit Care Med 2001;164:1508-13.

36 Kuschner WG, D'Alessandro A, Wong H, et al. Dose-dependent cigarette smoking-related inflammatory responses in healthy adults. Eur Respir J 1996;9:1989-94.

37 Barnes PJ, lto K, Adcock IM. Corticosteroid resistance in chronic obstructive pulmonary disease: inactivation of histone deacetylase. Lancet 2004;363:731-3 